\title{
Habits of Mind in the ESL Classroom
}

\author{
Maria Shu Hong Bee ${ }^{1}$, Goh Hock Seng ${ }^{2} \&$ Kamaruzaman Jusoff ${ }^{3}$ \\ ${ }^{1}$ SK Tanjong Malim, Perak, Malaysia \\ ${ }^{2}$ Department of English Language and Literature, Faculty of Languages and Communication, Universiti \\ Pendidikan Sultan Idris, Perak, Malaysia \\ ${ }^{3}$ Department of Forest Production, Faculty of Forestry, Universiti Putra Malaysia, Selangor, Malaysia \\ Correspondence: Kamaruzaman Jusoff, Department of Forest Production, Faculty of Forestry, Universiti Putra \\ Malaysia, 43400 UPM Serdang, Selangor, Malaysia. Tel: 603-89-467-176. E-mail: kjusoff@yahoo.com
}

\author{
Received: August 1, 2013 Accepted: September 4, 2013 Online Published: October 10, 2013 \\ doi:10.5539/elt.v6n11p130 URL: http://dx.doi.org/10.5539/elt.v6n11p130
}

\begin{abstract}
Engaging HoM means having the disposition toward behaving intelligently when confronted with problems, to which solutions are not immediately apparent. Employing HoM helps students to reason and apply information to solve problems in today's classrooms. This article examines the prominent HoM among primary school students as they interact to co-construct knowledge in group reading sessions. Talking and interacting with reading reinforce learning in a social context and such discussion reflects students' thinking. Qualitative data were analyzed and the findings indicated the presence of HoM. The research provides an insight as a means for teachers to develop the reading context into one that truly stimulates the individual and social co-construction of knowledge. By exploring the students' HoM, these dispositions of intelligent behaviours can perhaps be made explicit and taught in the ESL classroom.
\end{abstract}

Keywords: co-construction of knowledge, habits of mind, intelligent behaviours, group reading

\section{Introduction}

Learning in schools is traditionally dominated and controlled by teachers and therefore students seldom make decisions about their own learning (Goodlad, 2004). However, it should be noted that acknowledging the learner's active role does not diminish the important role of the teacher, but rather suggests that the teacher understands the student's point of view and prior knowledge in order to cultivate the most powerful learning experiences (Brooks \& Brooks, 1999; Gardner, 1991; Shapiro, 2004).

Many students in Malaysian schools excel academically in terms of multiple distinctions in examinations but, based on personal observations, it may also be said that there are many who have difficulties expressing their thoughts well and spontaneously. This may be due to the lack of opportunities in the classroom given to the students to think and to verbalize their opinions confidently in schools. Hence, to move to encourage active learning, thinking and decision making activities that will help to improve students' thinking should be given due attention.

In today's classrooms, it is important to engage thinking activities that enable students to go beyond the simple memorization and regurgitation of facts. Developing these thinking dispositions help students to understand, to reason and apply information to solve problems both in and out of the classroom. Particularly in English as Second Language (ESL) classrooms, verbal interaction or communication is a major key to learning a second language. Thus, there is a need to move from the traditional focus on how many answers a student knows to a focus on engaging Habits of Mind (HoM) as the learning outcome in a teaching and learning classroom.

Engaging HoM means having the disposition toward behaving intelligently when confronted with problems, to which solutions are not immediately apparent (Costa, 2000). He has suggested $16 \mathrm{HoM}$ drawn from research on human effectiveness, descriptions of remarkable performers, and analyses of

The characteristics of efficacious people. These $16 \mathrm{HoM}$ are attributes that human beings display when they behave intelligently to overcome difficult challenges and serve as mental disciplines. Costa (2000) believes that it is essential for students to engage in these intelligent behaviours and it is only through constant revisiting and acting with such behaviours that each proposed HoM will become a disposition. 
Costa \& Kallick (2004) noted that although HoM is generally presented without a solid theoretical basis, consideration of learning theories as well as theories on the nature of intelligence indicate that there are potentially strong connections to research based findings on learning. By attempting to make these theoretical underpinnings more explicit, they sought to present HoM as a potentially useful learning framework relevant to contemporary understandings of teaching and learning. In addition, learning is a social process rather than strictly a function of individual effort and intelligence (Vygotsky, 1986).

In effect, learners' co-construction of knowledge is observable in dialogues with parents, teachers, and peers (Perkins, 1999). The teaching and grouping strategies that give students opportunities to observe, verbalize, interact, and learn from each other in the process of completing academic tasks result in powerful learning outcomes (Cohen, 1994; Heyman, 2008; Palincsar \& Brown, 1984; Slavin, 1995). Therefore, collaborative and cooperative group instructions are effective techniques that foster cognitive and social development.

As Van Boxtel, et al. (2000) explain, collaborative learning activities allow students to provide explanations of their understanding, which can help students to elaborate and reorganize their knowledge. Under this view, knowledge is not something that is handed down from one student to another. Rather, knowledge is co-constructed through interactions among peers. The social interaction of students stimulates elaboration and co-construction of knowledge as peers attempt to make themselves understood and HoM are made visible through verbal exchanges as students negotiate meaning to arrive at shared understanding as they read collaboratively.

Surveying the related literature, however, shows that there is presently little empirical research on the use of HoM among ESL students in classroom settings. Hence, this study was carried out to explore the employment of HoM as a group of ESL primary school students interact to co-construct knowledge while reading collaboratively.

In tandem with the said aim, the study was driven by the following research questions:

1) Do young ESL students engage Habits of Mind (HoM) as they interact in collaborative reading?

2) If they do, what are the prominent HoM engaged by these students as they interact in collaborative reading?

\section{Method}

A case study was deemed appropriate since the study sought to examine the employment of HoM by a group of primary school students. As noted by Yin (2003) the case study is preferred in examining contemporary events when the relevant behaviours cannot be manipulated. This study documented the primary school students' HoM as they co-constructed knowledge while reading collaboratively in the ESL classroom through observations on students' responses, interactions and to view their intelligent behaviours termed as HoM (Costa, 2000).

\subsection{Participants}

The participants were a group of 12-year old Year Six primary school students with intermediate level of proficiency in English Language. They started learning English when they were in Year One. Purposeful sampling (Patton, 1990) was used in the selection of the six participants and based on various criteria, namely, experience in performing group reading, achievement in second language reading and also the ability to converse in English Language fairly well. The endeavor was to find a small, purposeful sample of information-rich cases. These selected students were a group of ethnic Malays; comprised four boys and two girls who were studying in a rural primary school.

\subsection{Procedure}

A total of five reading sessions were carried out. In the sessions, the participants were seated as a group, facing each other and they were asked to read English texts (one text for one session) that are appropriate for Year 5 and Year 6 in accordance to the Malaysian English Language syllabus. The students were required to first read the text individually and silently and thereafter they each took an envelope that contained a question. Each student would then read aloud the question in the envelope and shared his or her views or answers with the others in the group. As a group, the students discussed the possible answers to the questions. This was repeated for each question selected by the pupil in the group respectively. These discussions were carried out by the students themselves without any intervention from the researcher who were present with them as an observer.

The reading sessions were audio and video recorded. Additionally, field notes were made and a checklist (and description) of HoM was also used as a focus in identifying possible HoM seen utilized by the students.

Finally, focus group interviews with the participants were also conducted after all the five sessions were completed. Such data collection tools provided data that were used for triangulation purposes. 


\subsubsection{Data Analysis}

The data analysis involved, firstly, the earlier groundwork of devising the coding system and checking for inter-rater reliability. The coding of data from the reading transcriptions was the occurrences of patterns that were grouped according to the indicators of HoM. Secondly, two raters coded the transcribed field notes, audio and video recordings, focus group recordings and checklists for HoM. Inter-rater reliabilities for all the sessions were between 0.71-0.91.

The raters then reviewed each rendition together with the researcher to resolve disagreements in the identification of HoM categories. There were, inevitably, occasional disagreements in drawing the lines or boundaries between the HoM in each occurrence. Furthermore, some of the HoM were interwoven in 'clusters' whereby a few HoM coexist at a certain context when the affirming statements indicated more than one HoM. Examining the students' paralinguistic features through the video recordings helped in accurate identification of HoM as compared to the earlier categorization of HoM that depended solely on reading the transcriptions and listening to the audio recordings. Analysis of HoM observed was conducted in terms of frequency counts and percentages.

\section{Results}

As Costa posited, HoM are intelligent thinking behaviours used in solving problems. Such behaviours were indeed observed in the participants' group interactions when they were looking for the best solutions to the questions posed based on the reading texts. The collaborative act of reading was like a problem solving task in which students were engaged in. Analysis of the data indicated that the students engaged almost all the HoM listed by Costa (2000) as they interacted during the collaborative reading sessions.

For instance, the students were seen rereading the texts, pausing to think at intervals, attempting to state their points clearly, seeking clarification and trying to find the best answer to the questions posed. These behaviours are indications of employing HoM of various categories such as "HoM4: Thinking flexibly", "HoM1: Persisting" and "HoM9: Thinking and communicating with clarity and precision".

Table 1 below provides the list of HoM based on the frequency of occurrences that each was observed during the collaborative sessions. A total of 650 occurrences were observed and it can be seen from the table that the three most frequently used HoM were "HoM7: Questioning and posing problems" (17.0\%), "HoM9: Thinking and communicating with clarity and precision" (14.3\%) and "HoM8: Applying past knowledge to new situation" $(13.1 \%)$.

Table 1. Ranking of observed HoM

\begin{tabular}{lllcc}
\hline Rank & Habits of Mind (HoM) & Total & $\%$ \\
\hline 1 & HoM7 & Questioning and Posing Problems & 111 & 17.0 \\
2 & HoM9 & Thinking \& Communicating w. clarity & 93 & 14.3 \\
3 & HoM8 & Applying Past Knowledge & 85 & 13.1 \\
4 & HoM3 & Listening with understanding & 62 & 9.5 \\
5 & HoM12 Responding with wonderment \& awe & 56 & 8.6 \\
6 & HoM1 Persisting & 47 & 7.2 \\
7 & HoM15 Thinking Interdependently & 41 & 6.3 \\
8 & HoM14 Finding humour & 37 & 5.7 \\
9 & HoM11 Creating, imagining \& innovating & 29 & 4.5 \\
10 & HoM2 $\quad$ Managing Impulsivity & 24 & 3.7 \\
11 & HoM6 & Striving for accuracy & 21 & 3.3 \\
12 & HoM4 $\quad$ Thinking Flexibly & 18 & 2.8 \\
13 & HoM5 $\quad$ Metacognition & 12 & 1.9 \\
14 & HoM17 Predicting & 8 & 1.2 \\
15 & HoM10 Gathering data through all senses & 3 & 0.5 \\
16 & HoM16 Remaining open to cont. learning & 2 & 0.3 \\
17 & HoM13 Taking responsible risks & 1 & 0.2 \\
TOTAL & & 650 & 100 \\
\hline
\end{tabular}


This report focuses on the most prominent HoM, the observation of what we called 'clustering' and a new HoM17 is employed by students, not listed by Costa (2000) but observed in the data. Table 1 clearly shows that the most prominent HoM utilized as the students progressed through this collaborative act was "HoM7: Questioning and posing problems". The students were seen asking questions and giving comments to each other as they read and discussed the text. As Costa (2000) affirmed, effective problem solvers know how to ask questions to fill in the gaps between what they know and what they do not know.

Looking at the data in this study, the students asked a range of questions. The questions generated by students are clarification questions to define words or concepts, or requests for information to support the conclusions and assumptions of other group members. These questions can be seen in the following examples:

Wishes of Life! Of life! Why do you choose that name?* (RT1RQ1)

Why do you say that? (RT1RQ1)

How do you know it's true? (RT1RQ1)

Are you saying that not doing homework means not liking homework? (RT2HWQ1)

What is 'activate'? (RT2HWQ4)

What do you understand by 'homework'? (RT2HWQ5)

Can you read again, where did you get that answer? (RT4MaQ2)

Why so? Why you think that?* (RT4MaQ5)

(Note*: Grammatical errors were not corrected as examples are shown verbatim)

\section{Discussion}

It was clear that the students were generating questions, responding to questions and developing understandings in the process of co-constructing meanings. It may be said that the students' generated questions helped the students overcome possible confusion and lack of understanding about the information and opinions expressed by their peers and also enabled them to be actively engaged with the text. The questions posed by the group members also provoked their thinking and this helped the students to develop understanding as they employed higher-order thinking in resolving any ambiguity.

Growing evidences from studies (Billmeyer, 2006; Harvey \& Goudvis, 2000) suggest that though questioning challenges pupils' intellect and help them to understand, it is a skill that may not be easily acquired. Generally, most primary students tend to ask closed questions and such questions would not help in encouraging students to challenge their own thinking.

Hence, it is interesting to witness how this group of rural primary school students could ask thought provoking questions as seen in the examples. Evidently, they asked the questions because they were curious to find out more from their peers and perhaps this was due to the group dynamics.

It can be challenging when this group of young learners are encouraged to think for themselves. Unexpected thinking and reasoning skills can arise from developing HoM when these students are given a voice - a voice to question, to challenge, to construct and co-construct the meanings around them. This was illustrated in the first reading session. It was observed that as one of the group members (Ly) read aloud his question, "What is the writer's view of Malaysian rivers?" he pondered for a while, reread the question silently and then asked the group "What's the writer's view of Malaysian rivers, ok, what are your views?" (RT1RQ1). Question as such further stimulates the peers' thinking.

From the group reading session, Ly demonstrated that he was more engaged in utilizing "HoM 7: Questioning and posing problem". In addition, Ly was much more actively engaged in generating and posing questions to peers, providing comments on peers' questions, and reading and responding to peers' comments. The results showed that students gained greater understanding and retention of the text when they actively engaged in peer review in their question generation processes (King, 1994). It can be asserted that students' engagement in group reading is a critical factor in improving reading comprehension through question generation which is HoM7.

Allowing students to listen to the questions and the answers generated by their peers is effective in helping them verify and cross-examine their understanding. It echoed the findings in Pressley (2002) as well as Lan and Lin (2011), in that these processes served as the stimulus for students to engage in reading collaboratively.

When students develop these habits of intelligent behaviours or HoM, the results can be unpredictable. When they learn how to examine ideas within text, beyond text and ideas in the world they will also learn to examine 
you as the teacher or facilitator and what you say. As students are engaged in the process of question generation, they take an active role in comprehending the texts through organising, composing, and assessing each other's questions. Different from answering teacher generated questions, students assume the roles of question designers who are engaged in a high level of cognitive function to test their peers' understanding and in using their self-regulatory cognitive strategy (Palincsar \& Brown, 1984). The processes of organising, composing, and assessing each other's questions deepen students' reading comprehension and allow students to have more transactions with the texts (Yeh \& Lai, 2012).

The group reading session is most effective when it is participatory, collaborative and focuses more on constructing and co-constructing meanings rather than merely receiving information. Learning how to discuss in reasonable and reflective ways seems to help improve students' reasoning and problem solving skills. They can learn to express their views with confidence, to raise doubts and questions, and to challenge the thinking of others. Through engaging in group discussions, the HoM are prominently utilized as students learn how to generate questions and pose problems to stimulate thinking for discussion. These HoM are habituated through their reading engagements. Prominently, they explore and develop their own ideas and views as they apply past knowledge to new situation as they generate more ideas to their discussion. Not only that they explain, they argue their point of view with others as they think and communicate with clarity and precision. As they interact to co-construct knowledge, they listen and consider the views and ideas of others by listening to others with understanding and empathy. They are able to give reasons to what they think and believe as they think about their thinking or metacognition and making student thinking visible to them is one of the best approaches that can be implement in the classroom (Tanner, 2012). Thus, they continue to change their ideas in the light of good reasons and evidence as they think interdependently and remain open to continuous learning.

A closer analysis of the prominent HoM observed showed another important feature in which the HoM were utilized. It was found that the HoM were employed in 'clusters' whereby a few HoM would be frequently observed together. For instance, through the employment of "HoM7: Questioning and posing problems", the students activated their prior knowledge "HoM8: Applying past knowledge to new situations" in finding more information to support their understanding, to elaborate on their thoughts or to overcome uncertainties. Furthermore, throughout the ensuing discussions they would employ "HoM9: Thinking and communicating with clarity and precision" and "HoM3: Listening with understanding and empathy" as they sought to make sense of the text. Excerpt 1 below illustrates this point.

Excerpt 1

Ly: Your sisters and brothers usually let you punch them? That's not right to treat your brothers and sisters like that.

Du: They start fight with me, like when I see TV or read, my brother will throw things to.... me. So I can understand why Mark pull the blanket. He doesn't want a sister like mine, always disturb me.*

Iz: Oh! Really?

Du: Yes, I remember when my mother brings my first baby brother home. I also think my mother love me less. * (RT3MaQ5)

(Note*: Grammatical errors were not corrected)

From this excerpt, it can be seen that one of the group members (Du) employed "HoM8: Applying past knowledge to new situations" when he related what happened between his siblings and him. He went on to relate his past experiences about the fight he had with his brother and he brought the experience to the present situation by stating that he could understand Mark's reaction and feelings of not wanting a little sister. Another group member (Iz) exhibited her amazement, responded surprisingly and from her expression she was surprised that Du could understand Mark's (writer's) feelings. Du continued to share his past experiences of his first baby brother's homecoming in a sad tone as the others listened with understanding.

Additionally, based on Excerpt 1, the conversation initiated from the students who expressed their feelings about the issue of being a part of a family. The questions led to sharing of past experiences and thus the students listened with understanding. To be able to answer a question posed, the listener not only had to listen with understanding, he had to think and communicate with clarity to the exact past experiences that he wanted to share with his peers. In the context of the group discussion, the clusters of HoM were employed to co-construct shared understandings of an issue or to intelligently find solutions to answer their peers.

The application and the sharing of past knowledge is similar to Pressley's (2000) findings in his study on the processes involved with eighth grade students in the construction of shared understanding and the determination 
of applying background knowledge was very important in how well a group finally understood the topic. Pressley (2002) also found that these primary school students relied on their past knowledge that they brought to the situation to co-construct shared understanding with regards to confirming and accepting other ideas. The exhibited HoM being observed in this episode is a cluster of HoM such as "HoM8: Applying past knowledge to new situations", "HoM9: Thinking and communicating with clarity and precision", "HoM3: Listening with understanding and empathy", "HoM4: Thinking flexibly" and "HoM12: Responding with wonderment and awe".

In a way, such clustering is not surprising since many of the HoM are interdependent. In other words, they are not employed independently of each other. A HoM may lead to another HoM or is the result of a previous HoM employed. This clustering of the HoM inevitably led to the students being actively engaged with the text and in the group discussions. The students displayed various HoM which in turn helped them to keep control of and be engaged in their own inquiry. Such circumstances reflect interesting and engaging lessons during collaborative reading which help exhibit HoM and perhaps even develop certain HoM among the individual group members.

HoM fits well with the notion of constructivist learning. Constructivist learning environments tend to be collaborative, learner-centered and inquiry focused. The principles of constructivism are parallel to HoM, for example, metacognition, thinking interdependently, questioning and posing problems, managing impulsivity and gathering data through all senses.

From the observations, the discussions kept the students motivated. Firstly, as students construct their own meanings of their world, they employ metacognitive strategies such as reflection, planning and evaluation, as well as data gathering processes through their five senses. Secondly, social interaction provides opportunities for learners to clarify their thoughts and learn from others in a reciprocal manner. Finally, a questioning attitude serves the learner in terms of meaning-making and solving problems.

It should also be said, then, that the ability or skill in asking thought provoking questions is essential in ensuring that the students remain engaged with the texts as well as with the resulting group interaction. At times, the students also hesitated in asking questions fearing that the questions would be deemed as 'stupid' questions and thus reflecting negatively on them. Based on the interviews conducted, students felt that they may be judged according to the questions they asked and hence were sometimes hesitant. This finding will be further discussed in the next section where pedagogical implications are drawn based on the results of the study.

When students are asked to manage their own learning, their HoM are most observable in their interactions as they co-constructed knowledge. In this learning mode, students participated and were engaged actively in their learning process, constructing knowledge and comprehending the text. The learning process is constructive, interactive and cooperative rather than individualistic, competitive and passive. Besides promoting cooperation and interaction in the learning process, the results showed that the learning experience also inculcates teamwork, communication and interpersonal skills in the students. This provides the students with a richer learning environment whereby students can learn to become independent, autonomous and self-directed learners.

Looking at Table 1 again, there is a particular observed HoM that is not in Costa's (2000) list of sixteen HoM. The HoM concerned is the "HoM of Predicting" (Number fourteen in Table 1). There were 8 (1.2\%) occurrences and were employed by the four students: Ly, Du, Zek and Iz. When they were faced with difficulties in finding solutions, the students made predictions or intelligent guesses without giving up easily to the difficult tasks. This is another portrayal of intelligent behaviour or HoM by students when they are faced with challenges or obstacles in understanding the text.

Example of this "HoM of Predicting" can be seen in the following extracts:

Maybe maybe, she's an angel. (RT MH)

Maybe that's the way it is. Ya, I guess he's not happy well because he will not have true friends (RT Mark)

The boy can be very rich, maybe the great magician, billionaire magician. (RT Dg)

I rasa [feel] nobody can do a good job like her. I think she's going to be someone terkenal [famous]. (RT Hwk)

Predicting or 'educated guess' is when students are observed to put all the puzzles together and focus their thinking to create a picture of what is known. The "HoM of Predicting" goes one step beyond sequencing to look ahead into what has not happened and is based on known information. This "HoM of Predicting" engage students in deeper thinking about a situation.

As the students interacted among peers to confirm and elaborate their curiosity, the "HoM of Predicting" is a previewing strategy when the students hypothesize about the meanings of the text based on textual clues or their 
own experiences. The "HoM of Predicting" helped this group of students to set a goal for reading and focused their thinking. As observed, in times of finding solutions for a problem, the students demonstrated their employment of HoM as they collaborated while reading the texts.

When they read and think, the HoM helped students to construct meaning from the text and make connections to the real world. This enabled the students to co-construct knowledge collaboratively through the discussions and interactions. As this group of primary school students read, predict, think and talk, they are co-constructing knowledge in a learning circle that promotes interdependency and thinking.

Furthermore, as the responses in this study have shown, reading as a group gave the students opportunities to "think out loud" and experiment with thoughts that were not yet fully formed and to hear what other students have to say about their ideas. This accords Palincsar \& Brown's (1984) study on the use of reciprocal teaching to improve reading comprehension through the teaching of strategies namely question generation, summarization, clarification and prediction.

Additionally, Vygotsky (1986) believes that a child's mind can be enriched if he is placed in a situation with more knowledgeable people to talk to and had a wide array of experiences to count as his own. The findings in this study corroborate with the observed behaviours focusing on comprehension strategy instruction such as predicting or guessing that resulted in increased students' understanding of the text in an elementary classroom by Durkin (1978). Similarly, Vermette, Harper and Di Millo (2004) noted that learning is enhanced when students construct more powerful representations of their knowledge.

The employment of HoM by this group of primary school students as they actively collaborated to read were observable through their engagements in predicting and negotiating meanings, clarifying doubts and responding to questions. In short, the findings of this study suggest that the connection between group discussions and HoM in co-construction of knowledge have much to offer to learners of all ages, particularly in the ESL reading classroom.

The findings discussed above inevitably lead to a few pedagogical implications that need to be considered. Firstly, there is a need for teachers to create an environment that is conducive or 'non-threatening' for students to pose questions and interact in the reading group. Besides that, there may also be a need to provide adequate instructions and practice, particularly to students of low proficiency, in the area of asking questions that will require higher order thinking in the answers.

Another implication is that teachers themselves need to understand the different HoM well. Teachers need to be clear on what a particular HoM is and hence rely on their knowledge and experience to provide appropriate activities to nurture inquiring minds and dispositions for learning in the students they work with.

It is also important that teachers should know their students well so as to enable them to select certain HoM to focus and develop the HoM amongst their students. Perhaps teachers could identify a few frequently used and inter-related HoM to start with. Additionally, teachers must also consider whether to identify the HoM first and then plan the activity based on the HoM identified or they should plan the lessons for HoM in a sequence that matches pupils' developments, that is with increasing complexity. Hence, teachers can create an atmosphere in which students experience and practice the HoM. For example, by consistently demonstrating HoM as the students carry out group discussions, they can develop and improve the HoM that can be applied when they face problems in any situation.

\section{Conclusion}

HoM is presently an area that is not extensively researched. This study contributes to that area and has provided some insights pertaining to HoM amongst young ESL learners in the context of collaborative reading. It has been observed that young ESL learners do engage in HoM and there are strong indications of high levels of reasoning and critical thinking in activities that encourage group discussions. Young learners who read collaboratively are also more frequently found to generate new ideas, strategies, and solutions. Further research could look into the infusion of HoM in different groups of students such as struggling readers in ESL classroom. Besides that, future studies could also examine the impact of HoM on specific language skills such as speaking and writing. Finally, it is hoped that these dispositions of intelligent behaviours or HoM can be made explicit and valued in the ESL classroom.

\section{References}

Billmeyer, R. (2006). Strategies to engage the mind of the learner: Creating strategic learners (2nd ed.). Omaha, NE: Rachel \& Associates. 
Brooks, J. G., \& Brooks, M. G. (1999). In search of understanding: The case for constructivist classrooms. Alexandria, VA: Association for Supervision and Curriculum Development.

Cochran-Smith, M., \& Lytle, S. L. (2009). Inquiry as stance: Practitioner research for the next generation. New York: Teachers College Press.

Cohen, E. G. (1994). Restructuring the classroom: Conditions for productive small groups. Review of Educational Research, 64(1), 1-35. http://dx.doi.org/10.3102\%2F00346543064001001

Cohen, R. (1983). Self-generated questions as an aid to reading comprehension. The Reading Teacher, 36(8), 770-775. Retrieved http://www.jstor.org/discover/10.2307/20198324?uid=3738672\&uid=2\&uid=4\&sid=21102497563061

Costa, A. L. (Ed.) (2000). Developing minds: A resource book for teaching thinking. Alexandria, VA: Association for Supervision and Curriculum Development.

Costa, A. L., \& Kallick, B. (2004). Assessment strategies for self-directed learners. Thousand Oaks, CA: Corwin Press.

Durkin, D. (1978). What classroom observations reveal about reading comprehension instruction. Reading Research Quarterly, 14(4), 481-533. http://dx.doi.org/10.1598\%2FRRQ.14.4.2

Gardner, H. (1991). The unschooled mind. New York, NY: Basic Books.

Goodlad, J. I. (2004). A place called school. New York, NY: McGraw-Hill.

Harvey, S., \& Goudvis, A. (2000). Strategies that work. York, MN: Stenhouse Publishers.

Heyman, G. D. (2008). Children's critical thinking when learning from others. Current Directions in Psychological Science, 17(5), 344-347. http://dx.doi.org/10.1111\%2Fj.1467-8721.2008.00603.x

King, A. (1994). Autonomy and question asking: The role of personal control in guided student generated $\begin{array}{lllll}\text { questioning. Learning and Individual Differences, } & 6(2),\end{array}$ http://dx.doi.org/10.1016\%2F1041-6080\%2894\%2990008-6

Lan, Y. F., \& Lin, P. C. (2011). Evaluation and improvement of student's question-posing ability in a web-based learning environment. Australasian Journal of Educational Technology, 27(4), 581-599.

Palincsar, A. S., \& Brown, A. L. (1984). Reciprocal teaching of comprehen-sion-fostering and comprehension-monitoring activities. Cognition and Instruction, 1(2), 117-175. http://dx.doi/abs/10.1207/s1532690xci0102_1\#.UfOiRC1XjMw

Patton, M. Q. (1990). Qualitative evaluation and research methods (2nd ed.). Newbury Park, CA: Sage Publications.

Perkins, D. (1999). The many faces of constructivism. Educational Leadership, 57(3), 6-11.

Pressley, M. (2000). What should comprehension instruction be the instruction of? In M. L. Kamil, P. B. Mosenthal, P. D. Pearson, \& R. Barr (Eds.), Handbook of reading research (vol. 3, pp. 545-561). Mahwah NJ: Erlbaum.

Pressley, M. (2002). Reading instruction that works: The case for balanced teaching (2nd ed.). New York: Guilford Press.

Shapiro, A. M. (2004). Prior Knowledge Must Be Included as a Subject Variable in Learning Outcomes Research. $\begin{array}{llll}\text { American Educational } & \text { Research }\end{array}$ http://dx.doi.org/10.3102\%2F00028312041001159

Slavin, R. E. (1995). Cooperative learning: Theory, research, and practice (2nd ed.). Boston, MA: Allyn \& Bacon.

Tanner, K. D. (2012). Promoting student metacognition. CBE-Life Sciences Education, 11, 113-120.

Van Boxtel, C., Van der Linden, J., \& Kanselaar, G. (2000). Collaborative learning tasks and the elaboration of conceptual knowledge. Learning and Instruction, 10(4), 311-330. http://dx.doi.org/10.1016\%2FS0959-4752\%2800\%2900002-5

Vermette, P., Harper, L., \& Dimillo, S. (2004). Cooperative and collaborative learning with 4-8 year olds. How does research support teachers' practice? Journal of Instructional Psychology, 31(2), 130-135.

Vygotsky, L. S. (1986). Thought and language (A. Kozulin, Ed. \& Trans.). Cambridge, MA: MIT Press. 
Yeh, H. C., \& Lai, P. Y. (2012). Implementing online question generation to foster reading comprehension. Australasian Journal of Educational Technology, 28(7), 1152-1175.

Yin, R. K. (2003). Case study research, design and methods (3rd ed.). Newbury Park: Sage Publications.

\section{Copyrights}

Copyright for this article is retained by the author(s), with first publication rights granted to the journal.

This is an open-access article distributed under the terms and conditions of the Creative Commons Attribution license (http://creativecommons.org/licenses/by/3.0/). 